\title{
The "Diagonal" Lesion: A New Type of Combined Injury Pattern Involving the Impingement Fracture of Anteromedial Tibial Plateau and the Injury of Posterior Cruciate Ligament and Posterolateral Corner
}

\author{
Xu Li, MD $\quad$ Guanyang Song, MD ${ }^{1} \quad$ Yue Li, MD $\quad$ Xin Liu, MD ${ }^{1} \quad$ Hui Zhang, MD ${ }^{1} \quad$ Hua Feng, MD \\ ${ }^{1}$ Sports Medicine Service, Beijing Jishuitan Hospital, Beijing, China \\ Address for correspondence Hua Feng, MD, Sports Medicine Service, \\ Beijing Jishuitan Hospital, No. 31, Xin Jie Kou East Street, Xi Cheng \\ J Knee Surg 2020;33:616-622. \\ District, Beijing, China (e-mail: fenghua20080617@126.com).
}

\begin{abstract}
The purpose of this study was to investigate the incidence and clinical characteristics of the "diagonal" lesion. A total of 273 consecutive patients with combined posterolateral corner (PLC) and posterior cruciate ligament (PCL) injuries were retrospectively analyzed. All preoperative knee joint evaluations were reviewed including the computed tomography, the anteroposterior (AP) view, the lateral view, the full-length long-standing AP view, and the physical examination results with the patient under anesthesia. Twenty-six patients (9.5\%) were verified as having the "diagonal" lesions. The anteromedial impingement fractures could be categorized into small (small fracture group, $n=7$ ) and large (large fracture group, $n=19)$. The PCL injuries were classified into grade $2(n=22)$ and grade 3 $(n=4)$. The PLC injuries could be classified into type $\mathrm{A}(n=3)$, type $\mathrm{B}(n=8)$, and type $\mathrm{C}$ ( $n=15$ ) according to the Fanelli's classification system. Notably, there were 20 chronic cases. Among them, 14 (70\%) had varus deformities. The proportion of patients with varus deformity in the large fracture group was significantly higher than that of the small fracture

Keywords

- diagonal lesions

- impingement fracture

- posterolateral corner group $(p=0.026)$. In this study, the incidence of the "diagonal" lesions was $9.5 \%$. Patients who had larger fracture size tended to develop subsequent varus deformity of the lower extremity. It was important for us to recognize the PCL/PLC injuries and to fully reduce the large bony fracture during the initial treatment of the "diagonal" lesions to prevent the residual instability and varus deformity.
\end{abstract}

The peripheral fracture of the anteromedial tibial plateau may reflect combined soft tissue injuries around the knee joint. It has been described in two kinds of patterns. The first is a cortical avulsion of the rim of the medial plateau by deep capsular ligament, referred to the "medial" or "reverse" Segond fracture, which is consistently combined with posterior cruciate ligament (PCL) injury ${ }^{1,2}$ and the second is an impingement fracture which was first described by Cohen et $\mathrm{al}^{3}{ }^{3}$ a radiographic sign implied combined posterolateral corner (PLC) and PCL injuries. They hypothesized the injury mechanism to be a combination of hyperextension, varus rotation, and posterior tibial translation.

received

March 17, 2018

accepted after revision

February 5, 2019

published online

March 27, 2019
The impingement fracture of the anteromedial tibial plateau has received ever-increasing attention in the literature. To the best of our knowledge, only a few case reports had given brief introductions to this combined injury pattern. In 2001, Chiba et $\mathrm{al}^{4}$ reported a case series of 12 patients and classified the anteromedial compression fracture size of tibial plateau into two types by plain radiography: small (less than a quarter of anteroposterior [AP] diameter of medial tibial plateau) and large (more than a quarter of that). In 2003, Bennett et $\mathrm{al}^{5}$ performed a magnetic resonance imaging (MRI) study and found such combined injury in six knees. In 2007, Engelsohn et $\mathrm{al}^{6}$ reported two cases of such combined injury with

Copyright $\odot 2020$ by Thieme Medical Publishers, Inc., 333 Seventh Avenue, New York, NY 10001, USA. Tel: $+1(212) 760-0888$
DOI https://doi.org/ 10.1055/s-0039-1683921. ISSN 1538-8506. 
associated medial meniscal root tears. In 2009, Yoo et $\mathrm{al}^{7}$ reported a case and confirmed the association between small bony lesion and major ligamentous injury.

Theoretically, the PCL, the PLC, and the anteromedial tibial plateau are all located along the axis connecting the anteromedial margin and the posterolateral aspect of the tibial plateau. The combined injury pattern involving all those structures could be simply termed as the "diagonal" lesion. To our knowledge, there are lacks of clinical case series study reporting its incidence and clinical characteristics.

The purpose of this study was therefore to investigate the incidence and clinical characteristics of the "diagonal" lesion. The hypothesis was that larger fractures were more likely to have complete PCL/PLC ruptures, knee joint subluxation, and varus deformity.

\section{Materials and Methods}

From January 2007 to December 2017, a total of 273 consecutive patients with more than grade 2 PCL/PLC injuries of the knee joints were treated in our department. All preoperative radiographs of the knee joint were retrospectively analyzed to investigate the incidence of the "diagonal" lesion.

Regarding the definition of the "diagonal" lesion, the associated fractures had to involve the anteromedial aspect of medial tibial plateau with the bony fragment significantly displaced. However, the medial avulsion fractures, as referred to a "reverse" or "medial" Segond fracture, were excluded.

The exact inclusion criteria were patients who had combined posterolateral and posterior instabilities of the knee joint; a confirmed anteromedial tibial fracture based on radiographic images. The exclusion criteria included avulsion medial tibial fracture and previous trauma or surgery history.

\section{Evaluation Methods}

The preoperative standard radiographs of knee joint, including the computed tomography (CT) scan, the MRI scan, the AP view, the lateral view, and the full-length weight-bearing long-standing AP view were reviewed. In addition, the physical examination results with the patient under anesthesia were further analyzed. This study was approved by the Institutional Review Board of our hospital (No. 2674).

\section{Computed Tomography Scans}

The CT scans were performed on an Aquilion ONE scanner (Toshiba Medical Systems, Tustin, CA). Axial CT scans and three-dimensional (3D) CT were used to quantify the size of the anteromedial impingement fracture of medial tibial plateau. The size of the fracture was classified into small and large according to the length of the fragment in the anteromedial-posterolateral direction (-Fig. 1).

\section{Plain Radiographies}

Standard plain radiography of knee joint, including the AP view, the lateral view, the bilateral full-length weight-bearing longstanding AP view were analyzed to assess the involved knee joint congruence and the bony alignment of the lower extremity.

\section{Magnetic Resonance Imaging Scans}

The MRI scans were performed on a standard 1.5-T superconducting magnet unit (Sigma; GE Medical Systems) using a standardized institutional protocol.

\section{Physical Examinations}

The senior author (X.L.) individually conducted the preoperative physical examinations for each patient and personally recorded the results. Posterior stress radiography with Telos equipment (Telos GmbH, Marburg, Germany) was performed to evaluate the posterior instability and was quantified as negative, grade 1,2 , or 3 according to the International Knee Documentation Committee knee evaluation form. Dial test and varus stress test were used to evaluate the combined PLC injuries. The dial test was performed with the patients in the supine position. The results of varus stress test at 30 degrees of knee flexion and varus stress radiography were used to determine the status of lateral collateral ligament (LCL). In this study, the PLC injury could be categorized into type A (excessive external rotation only), type $\mathrm{B}$ (excessive external rotation with partial tear of $\mathrm{LCL}$ ), and type $\mathrm{C}$ (excessive external rotation with complete tear of LCL) based on the Fanelli's classification system. ${ }^{8}$

\section{Data Management and Statistical Analysis}

Descriptive statistics were calculated for the demographic data, grade of PCL injury, the type of PLC injury, the anteromedial impingement fracture size, and the bony alignment status of the knee joint. The Pearson's chi-square test or Fisher's exact test was used to compare the categorical variables. The Student's $t$-test was used to compare the continuous variables. Analyses were performed using SPSS 18.0 software package (SPSS Inc., Chicago, IL). The $p$-values less than 0.05 were considered statistically significant.

\section{Results}

Among the 273 consecutive patients, 26 (9.5\%) were verified as having the "diagonal" lesion. The mean age was $28.5 \pm 8.9$ years (range, 16-52 years). Six cases suffered from acute injury and 20 cases suffered from chronic injury. The demographic data are summarized in - Table 1. In addition, the PCL injury could be classified into grade $2(n=4)$ and grade 3 $(n=22)$ based on the results of Telos stress radiography. The PLC injury could be categorized into type A $(n=3)$, type B $(n=8)$, and type $C(n=15)$ according to the Fanelli's classification system (-Table $\mathbf{1}$ ).

For the size of anteromedial compression fracture of the medial tibial plateau, 7 cases were defined as small (small fracture group) and 19 cases were defined as large (large fracture group). Proportion of patients who had varus malalignment of the lower extremity was $68.4 \%$ (13/19), which was significantly higher than that of the small group (14.2\%, $1 / 67)(p=0.026)$ (-Fig. 2). However, there was no significant difference between the two groups in terms of the degree of PLC injuries ( $p=0.543$ ) and the posterolateral knee joint subluxation ( $p=0.375$ ) (-Table 2 ). 
A
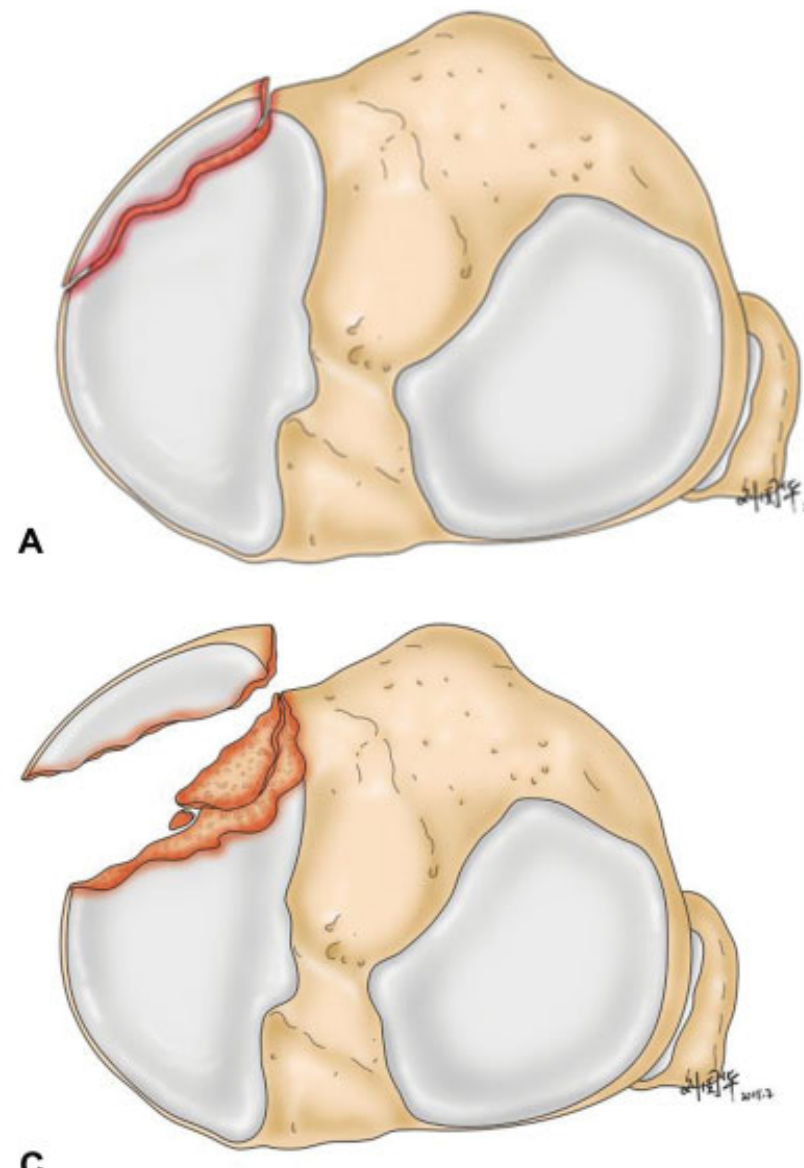

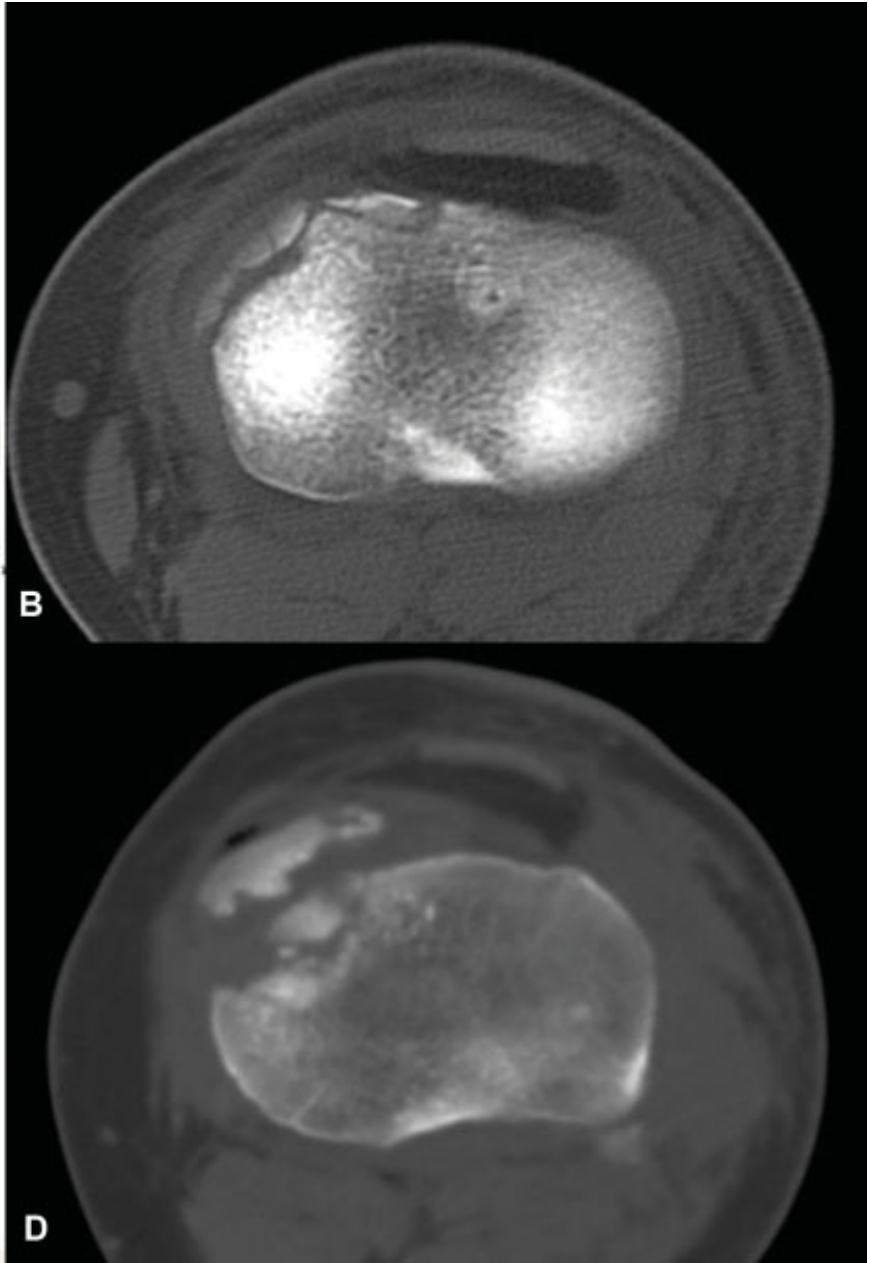

D

Fig. 1 The size of the fracture was classified into two types, according to the length of the fragment in the anteromedial-posterolateral direction. (A, B) Small type: a quarter or less of the anteromedial tibial plateau; (C, D) large type: more than a quarter of the anteromedial tibial plateau.

Among the 20 patients who had chronic injury, 14 (70\%) had previous surgeries of the involved knee joint. Analyses of the reason for the primary failed surgeries demonstrated that 11 of them did not have the PLC injury addressed during the previous surgery and 13 of them did not have the large anteromedial impingement fracture fully reduced.

\section{Discussion}

The most important findings of this study were as follows: (1) The incidence of "diagonal" lesions was 9.5\%. (2) Patients with larger fracture size tended to have higher proportion of varus deformity of the lower extremity.

Previous studies highlighted the importance of early recognition of this special combined injury pattern for the proper surgical plans. ${ }^{3-7}$ In the present study, 78.6\% (11/14) of the patients who received previous surgeries still complained of residual instability had unrecognized PLC injuries during the initial treatment of the anteromedial impingement fracture of the tibial plateau. Moreover, our study confirmed the findings of previous studies and described further information regarding the sequela of the "diagonal" lesion.
One of the sequelae of the chronic "diagonal" lesion in our study was residual varus deformity and even knee joint subluxation. Further analyses revealed that the main reason of that was inadequate initial reduction of the anteromedial impingement fracture. Furthermore, the fact that all but one fracture was large size, and the results of statistical analyses demonstrated that patients with a larger fracture size tended to develop residual varus malalignment. Therefore, primary reduction of displaced large fracture was a critical step in preventing residual varus deformity.

In this study, $84.6 \%(22 / 26)$ of the patients had grade $3 \mathrm{PCL}$ injury and $88.5 \%(23 / 26)$ had type B/C PLC injury, indicating that high-velocity forces of hyperextension and varus rotation applied during the initial injury. It could be speculated that the combined forces exerted on the anteromedial margin of the tibial plateau transferred along the posterolateral direction, producing tensile disruptions of the posterolateral soft tissue and resulting in the compression fracture of the anteromedial tibial plateau. Although there was no significant difference between the small fracture group and the large fracture group in terms of the PLC injury type $(p=0.543)$, most of the patients in the large fracture group had LCL injuries. Patients who had LCL insufficiency and large 
Table 1 Patient demographics, associated injuries, anteromedial tibial plateau fracture size, PCL/PLC injuries, joint congruence, and lower extremity alignment

\begin{tabular}{|c|c|c|c|c|c|c|c|c|c|c|}
\hline Patient & Sex & $\begin{array}{l}\text { Age } \\
\text { (y) }\end{array}$ & $\begin{array}{l}\text { Acute or } \\
\text { chronic }\end{array}$ & $\begin{array}{l}\text { Causes of } \\
\text { injury }\end{array}$ & $\begin{array}{l}\text { Associated } \\
\text { injuries }\end{array}$ & $\begin{array}{l}\text { Fracture } \\
\text { size }\end{array}$ & $\begin{array}{l}\mathrm{PCL} \\
\text { (grade) }\end{array}$ & $\begin{array}{l}\text { PLC } \\
\text { (type) }\end{array}$ & $\begin{array}{l}\text { Posterolateral } \\
\text { subluxation }\end{array}$ & Varus \\
\hline $1 \mathrm{LJ}$ & M & 26 & Acute & Motorcycle & None & Small & 3 & A & No & No \\
\hline 2SAM & $M$ & 41 & Chronic & Car accident & Multiple fracture & Large & 3 & A & yes & Yes \\
\hline $3 Y W$ & $M$ & 31 & Acute & Crush injury & CPN & Small & 3 & $C$ & No & No \\
\hline $4 Y G H$ & M & 31 & Chronic & Car accident & $\begin{array}{l}\text { Hoffa fracture, } \\
\text { ACL, MCL }\end{array}$ & Large & 3 & B & No & No \\
\hline $5 Z X W$ & $M$ & 18 & Acute & Motorcycle & $\begin{array}{l}\text { ACL, MCL, } \\
\text { CPN, DVT }\end{array}$ & Small & 3 & $\mathrm{C}$ & No & No \\
\hline $6 \mathrm{HJD}$ & M & 27 & Chronic & Car accident & $\begin{array}{l}\text { ACL, Pelvic } \\
\text { fracture, CPN }\end{array}$ & Large & 3 & C & Yes & Yes \\
\hline $7 \mathrm{WXM}$ & $\mathrm{F}$ & 26 & Chronic & Car accident & Popliteal vessels & Small & 3 & $\mathrm{C}$ & No & No \\
\hline 8WGQ & $M$ & 37 & Chronic & Car accident & $\begin{array}{l}\text { MM, MFC cartilage } \\
\text { fracture }\end{array}$ & large & 3 & $C$ & No & No \\
\hline $9 W X L$ & $M$ & 21 & Chronic & Car accident & $\begin{array}{l}\text { Multiple fracture, } \\
\text { popliteal vessels, } \\
\text { sciatic nerve }\end{array}$ & Large & 3 & B & No & No \\
\hline 10SMW & $M$ & 20 & Chronic & Car accident & ACL, LM, MM & Large & 3 & $C$ & No & Yes \\
\hline $11 S X Y$ & $M$ & 22 & Chronic & Twisted injury & $\begin{array}{l}\text { MCL, PMC, LM, MM, } \\
\text { popliteal vessels }\end{array}$ & Large & 3 & $A$ & Yes & Yes \\
\hline $12 \mathrm{~J} X \mathrm{C}$ & $M$ & 38 & Chronic & Fall from height & $\mathrm{ACL}, \mathrm{LM}, \mathrm{CPN}$ & Large & 3 & $C$ & Yes & Yes \\
\hline 13DP & $\mathrm{M}$ & 29 & Acute & Car accident & $\mathrm{ACL}, \mathrm{MM}, \mathrm{CPN}$ & Small & 3 & C & No & No \\
\hline $14 \mathrm{XFY}$ & M & 52 & Chronic & Car accident & $\mathrm{ACL}$ & Large & 3 & C & No & No \\
\hline 15LZM & M & 19 & Acute & Sports injury & None & Small & 2 & B & No & No \\
\hline $16 \mathrm{WF}$ & $\mathrm{M}$ & 19 & Chronic & Fall from height & $\mathrm{ACL}$ & Large & 3 & B & No & No \\
\hline $17 \mathrm{LBF}$ & $\mathrm{M}$ & 41 & Chronic & Car accident & $\mathrm{ACL}$ & Small & 3 & C & Yes & Yes \\
\hline $18 X S H$ & M & 24 & Chronic & Car accident & $\mathrm{ACL}$ & Large & 3 & C & Yes & Yes \\
\hline $19 Z Y$ & $M$ & 41 & Chronic & Car accident & $\mathrm{ACL}$ & Large & 3 & C & Yes & Yes \\
\hline $20 L Y$ & $\mathrm{M}$ & 24 & Chronic & Car accident & ACL, CPN & Large & 3 & C & No & Yes \\
\hline 21LJW & M & 32 & Chronic & Twisted injury & $\mathrm{ACL}, \mathrm{CPN}$ & Large & 2 & B & Yes & Yes \\
\hline 22WYD & $\mathrm{M}$ & 16 & Acute & Fall from height & $\mathrm{ACL}, \mathrm{CPN}$ & Large & 3 & $C$ & No & No \\
\hline 23JJL & $\mathrm{M}$ & 27 & Chronic & Car accident & CPN & Large & 2 & B & No & Yes \\
\hline 24LFS & M & 33 & Chronic & Car accident & $\mathrm{ACL}$ & Large & 3 & C & No & Yes \\
\hline $25 R W C$ & $M$ & 27 & Chronic & Car accident & $\begin{array}{l}\text { ACL, femoral } \\
\text { shaft fracture }\end{array}$ & Large & 2 & $B$ & No & Yes \\
\hline $26 S S C$ & $M$ & 19 & Chronic & Car accident & $\mathrm{ACL}$ & Large & 3 & B & No & Yes \\
\hline
\end{tabular}

Abbreviations: ACL, anterior cruciate ligament; CPN, common peroneal nerve; DVT, deep venous thrombosis; LM, lateral meniscus; MCL, medial collateral ligament; MFC, medial femoral condyle; MM, medial meniscus; PCL, posterior cruciate ligament; PLC, posterolateral corner.

fracture size tended to develop a residual varus deformity of the lower extremity after the "diagonal" lesion.

The 14 patients who had failed previous surgery complained about instability or varus deformity of the lower extremity. Further analyses showed that a majority of residual instability (11 of 14 ) were due to either failure of recognition of the PLC injuries or unsatisfied reduction of the large fracture during the initial treatment. Regarding the treatment of fractures, 13 of them were large and displaced pattern in which the anatomic reduction and internal fixation were necessary. Unfortunately, 10 of them were left untreated and 3 were not fully reduced. Therefore, the present study stressed the initial management rationale of lesion recognition, adequate judgment, and appropriate surgery for both ligament injuries and bony fractures.

The tibial plateau fracture may combine with soft tissue injuries around the knee joint. ${ }^{9-11}$ Abdel-Hamid et al ${ }^{9}$ stated that $71 \%$ of tibial plateau fractures had some associated soft tissue injuries, and the ACL injury was the second most common injury, mainly in types IV and VI tibial plateau fractures. Huang et al ${ }^{10}$ also confirmed that the cruciate and collateral ligaments could be observed in types V and VI tibial plateau fractures. Tang et a ${ }^{11}$ calculated that the threshold of the ACL avulsion fracture associated with medial tibial 


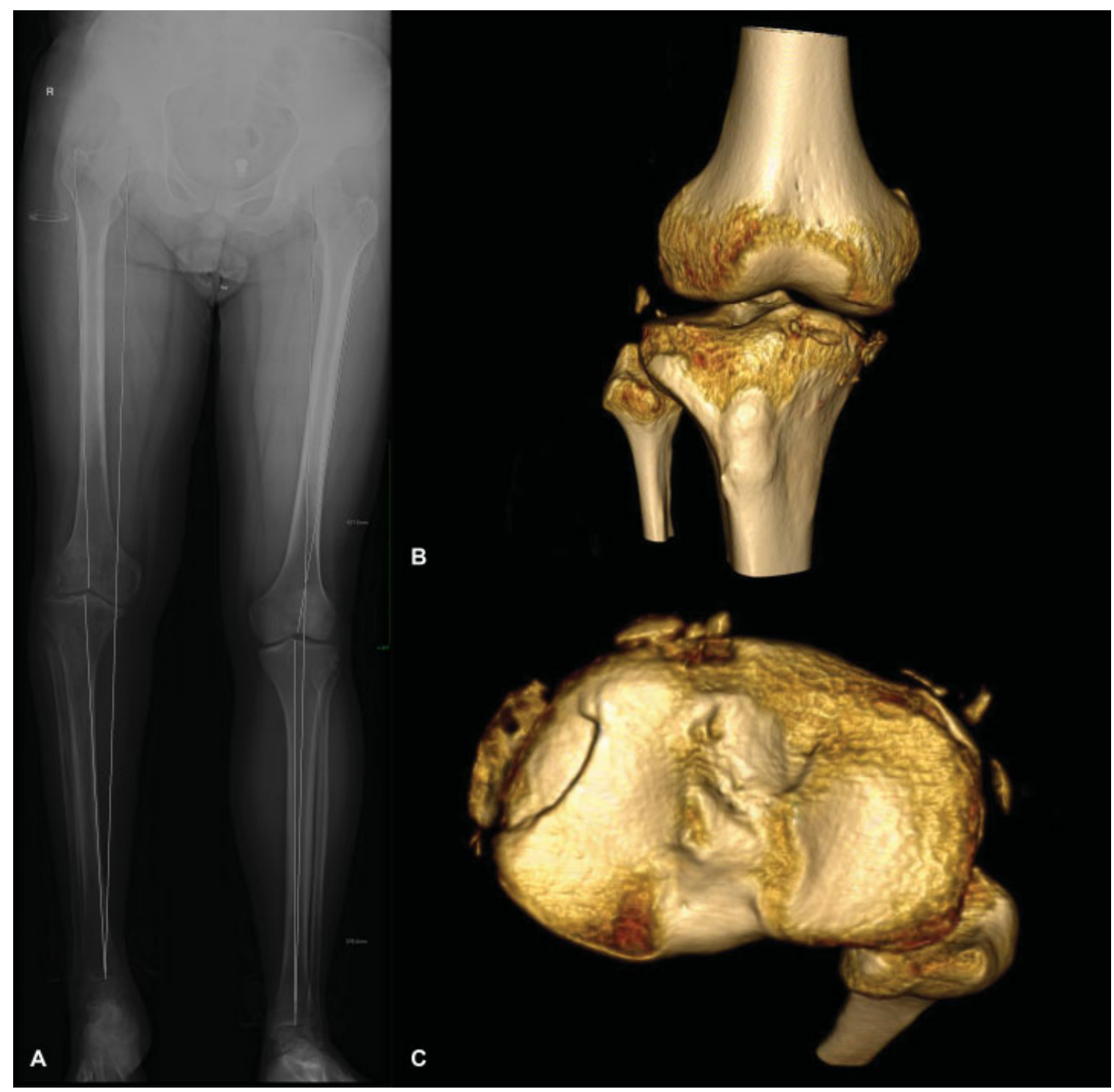

Fig. 2 A 21-year-old man who sustained an chronic anteromedial impingement fracture. (A) Full-length standing radiograph demonstrated varus deformity of the affected limb; (B) coronal 3D CT shows wide opening of the lateral compartment and the small impaction fracture fragment is medial to the tibial plateau; and (C) axial 3D CT shows the fragment was anteromedial to the tibial plateau. CT, computed tomography; 3D, three-dimensional.

Table 2 Comparison between the small fracture group and the large fracture group

\begin{tabular}{|c|c|c|c|}
\hline Variables & $\begin{array}{l}\text { Small fracture } \\
\text { group }(n=7)\end{array}$ & $\begin{array}{l}\text { Large fracture } \\
\text { group }(n=19)\end{array}$ & p-Values \\
\hline \multicolumn{4}{|l|}{ PLC type, $n$} \\
\hline Type A & 1 & 2 & \multirow[t]{3}{*}{0.543} \\
\hline Type B & 1 & 7 & \\
\hline Type C & 5 & 10 & \\
\hline \multicolumn{4}{|c|}{ Knee subluxation, $n$} \\
\hline Present & 1 & 7 & \multirow[t]{2}{*}{0.375} \\
\hline Absent & 6 & 12 & \\
\hline \multicolumn{4}{|c|}{ Varus deformity } \\
\hline Present & 1 & 13 & \multirow[t]{2}{*}{0.026} \\
\hline Absent & 6 & 6 & \\
\hline
\end{tabular}

Abbreviation: PLC, posterolateral corner. plateau displacement was $3 \mathrm{~mm}$. However, in our study, the tibial plateau fractures combined mainly the PCL/PLC injuries, suggested that the anteromedial tibial plateau fracture in diagonal lesion had a different injury mechanism compared with that of the traditional tibial plateau fractures. This also requires extra-attention to the treatment of the diagonal lesions.

There were some limitations to our study. First, as most diagonal lesions included in this study were chronic, the overall incidence in the general population remained unknown. Second, the sample size was relatively small, only simple statistical comparisons were performed and might be underpowered. Third, this was a retrospective study.

\section{Conclusion}

In this study, the incidence of the "diagonal" lesions was 9.5\%. Patients who had larger fracture size tended to develop 
subsequent varus deformity of the lower extremity. It was important for us to recognize the PCL/PLC injuries and to fully reduce the large bony fracture during the initial treatment of the "diagonal" lesions to prevent the residual instability and varus deformity.

\section{Funding}

This study was supported by the Beijing Municipal Science and Technology Commission, P.R. China, Z15110000401 5102.

\section{Conflict of Interest}

None declared.

\section{References}

1 Hall FM, Hochman MG. Medial Segond-type fracture: cortical avulsion off the medial tibial plateau associated with tears of the posterior cruciate ligament and medial meniscus. Skeletal Radiol 1997;26(09):553-555

2 Escobedo EM, Mills WJ, Hunter JC. The "reverse Segond" fracture: association with a tear of the posterior cruciate ligament and medial meniscus. Am J Roentgenol 2002;178(04):979-983

3 Cohen AP, King D, Gibbon AJ. Impingement fracture of the anteromedial tibial margin: a radiographic sign of combined poster- olateral complex and posterior cruciate ligament disruption. Skeletal Radiol 2001;30(02):114-116

4 Chiba T, Sugita T, Onuma M, Kawamata T, Umehara J. Injuries to the posterolateral aspect of the knee accompanied by compression fracture of the anterior part of the medial tibial plateau. Arthroscopy 2001;17(06):642-647

5 Bennett DL, George MJ, El-Khoury GY, Stanley MD, Sundaram M. Anterior rim tibial plateau fractures and posterolateral corner knee injury. Emerg Radiol 2003;10(02):76-83

6 Engelsohn E, Umans H, Difelice GS. Marginal fractures of the medial tibial plateau: possible association with medial meniscal root tear. Skeletal Radiol 2007;36(01):73-76

7 Yoo JH, Kim EH, Yim SJ, Lee BI. A case of compression fracture of medial tibial plateau and medial femoral condyle combined with posterior cruciate ligament and posterolateral corner injury. Knee 2009;16(01):83-86

8 Fanelli GC, Feldmann DD. Management of combined ACL/PCL/ posterolateral complex injuries of the knee. Oper Tech Sports Med 1999;7:143-149

9 Abdel-Hamid MZ, Chang CH, Chan YS, et al. Arthroscopic evaluation of soft tissue injuries in tibial plateau fractures: retrospective analysis of 98 cases. Arthroscopy 2006;22(06):669-675

10 Huang P-H, Cheng C-Y, Chen Y-J, et al. Reasons for failure of surgical treatment in 25 tibial plateau fractures. Formosan Journal of Musculoskeletal Disorders. 2012;3:14-18

11 Tang HC, Chen IJ, Yeh YC, et al. Correlation of parameters on preoperative $\mathrm{CT}$ images with intra-articular soft-tissue injuries in acute tibial plateau fractures: a review of 132 patients receiving ARIF. Injury 2017;48(03):745-750 
